\title{
Dünnschichtchromatographischer Nachweis von Cholinesterase
}

\author{
Von K. H. Goll und J. Gartzke \\ Aus dem Medizinisch-Diagnostischen Institut „Unter den Linden" (Leiter: Dr. K. H. Goll), Berlin
}

(Eingegangen am 8. November 1969 / 21. Scptember 1970)

Mit Hilfe der Dünnschichtchromatographie gelingt eine gute Trennung von Acetylcholin und Cholin, wodurch der Substratumsatz des Acetylcholins durch Serumcholinesterase gemessen und somit dic Fermentaktivität bestimmt werden kann.

\section{Determination of cholinesterase by thin layer chromatograpby}

Acetyl choline and choline can be separated by thin layer chromatography. Thus the hydrolysis of acetyl choline by serum cholinesterase can be measured and the enzymic activity determined.

Die Bestimmung der Serumcholinesterase ist sowohl für klinische als auch für toxikologische und arbeitshygienische Fragestellungen von Bedeutung (1-5). Die bisher üblichen Bestimmungsmethoden basieren fast ausschließlich auf dem Prinzip, die durch Cholinesterase aus Acetylcholin abgespaltene Essigsäure mittels Titration, $\mathrm{pH}-\mathrm{Messung}$ oder Kolorimetrie zu bestimmen, und daraus die Aktivität der Serumcholinesterase zu berechnen (6-16). Eine solche von SCHÄFER bearbeitete kolorimetrische Methode wurde kürzlich für die DDR als Standardmethode eingeführt (17). Außer der abgespaltenen Essigsäure kann ebensogut das freiwerdende Cholin bzw. die Abnahme des Acetylcholins als Meßgröße für die Aktivität der Serumcholinesterase dienen. Dazu ist erforderlich, das Cholin einwandfrei vom Acetylcholin zu trennen. Entsprechende Versuche mit einer papierchromatographischen Methode wurden von HomanN (18) publiziert. Die Trennung läßt sich jedoch am besten mittels der Dünnschichtchromatographie erreichen $(19,20,21)$. Das Prinzip der Methode besteht darin, daß Acetylcholin mit Serum in Gegenwart von Veronalpuffer $\mathrm{pH} 8,6$ inkubiert wird und somit die während der Inkubation abgespaltene Essigsäure abgepuffert und das $\mathrm{pH}$ bei etwa 8 gehalten wird. Das $\mathrm{pH}$-Optimum für die Cholinesterase liegt bei 8,5. Die Reaktion wird mit Physostigmin gestoppt und ein aliquoter Teil des Inkubationsgemisches auf $\mathrm{Al}_{2} \mathrm{O}_{3}$ - oder Cellulose $\mathrm{MN}$ 300-Dünnschichtplatten aufgetragen. Zum Vergleich dient ein Ansatz, dem das Physostigmin vor dem Serum zugegeben wird. Dieser Ansatz dient zur Eliminierung des Fehlers durch die nicht enzymatische Hydrolyse. Die Abnahme des Acetylcholins ist bei geeignet gewählter Ausgangskonzentration in $\mu \mathrm{Mol}$ Substratumsatz/Min. zu messen und somit in Milliunits anzugeben.

\section{Methodik}

$0,1 \mathrm{~m} /$ Serum werden mit $0,2 \mathrm{ml}$ einer $50 \mathrm{mM}$ AcetylcholinchloridPufferlösung $10 \mathrm{Min}$. bei $37^{\circ}$ inkubiert und anschließend mit $0,2 \mathrm{~m} l$ einer $17 \mathrm{~mm}$ Physostigminlösung versetzt. $20 \mu l$ des Ansatzes werden auf DC-Platten aus $\mathrm{Al}_{2} \mathrm{O}_{3}$ aufgetragen und mit dem Lösungsmittelgemisch Benzol/Äther/Methanol 40:20:40 (v/v) getrennt. Bessere Trennungen, aber bei längerer Laufzeit, lassen sich auf Cellulose MN 300-Platten mit dem Laufmittel n-Butanol/ Wasser/Ameisensäure 60:35:15 ( $\nabla / v)$ erzielen. Das Besprühen der Platte erfolgt nach vorhergehender Trocknung an der Luft mit einem DragendorfF-Reagenz nach MUNIER oder BREgofF (19), so daß ausschließlich tertiäre und quaternäre Stickstoffbasen erfaßt werden. Noch bessere Färbung erreicht man mit Dipikrylamin $0,2 \%$ in 50 proz. wäßr. Acetonlösung (19). Die quantitative Auswertung erfolgt densitometrisch mit Blaufilter, indem die Integrationswerte für den Leeransatz mit dem Analysenansatz verglichen und damit der Substratumsatz in Prozenten ausgedrückt werden. Zur einfachen Berechnung wurde im Inkubationsansatz eine Substratmenge von $10 \mu \mathrm{Mol}$ gewählt.

\section{Berechnung}

Substratlösung: $0,2 \mathrm{ml} \quad 50 \mathrm{~mm}$ AcetylcholinchloridPufferlösung (915 mg Acetylcholinchlorid mit 0,05M Veronalpuffer $\mathrm{pH} 8,6$ auf $100 \mathrm{~m} l$ auffüllen) werden mit $0,1 \mathrm{~m} l$ Serum inkubiert. $0,2 \mathrm{~m} l$ Substrat-Pufferlösung entsprechen 1,83 mg Acetylcholinchlorid bzw. $10 \mu \mathrm{Mol}$. Zur Umrechnung auf Units $/ l(\mathrm{U} / l=$ Substratumsatz in $\mu \mathrm{Mol} / \mathrm{Min} . \cdot\left(\right.$ bei $37^{\circ}$ ) von $0,1 \mathrm{~m} l$ Serum auf $1000 \mathrm{ml}$, von 10 Min. auf $1 \mathrm{Min}$. ist das Ergebnis mit $\frac{10000}{10}=10^{3}$ zu multiplizieren.

\section{Beispiel}

Gemessener Substratumsatz 75\%. Das ist bei einem Ansatz von $10 \mu \mathrm{Mol}=7,5 \mu \mathrm{Mol}=7,5 \cdot 10^{3} \mathrm{U} / \mathrm{l}$. Es entspricht also in jedem Falle der gemessene Substratumsatz, in Prozent multipliziert mit 100 dem Wert in Units pro $l$. 


\section{Literatur}

1. Goll, K. H., Dtsch. Gesdwes. 17, 950 (1962). - 2. Goll, K. H., Dtsch. Gesdwes. 17, 1326 (1962). - 3. Goll, K. H., Dtsch. Gesdwes. 18, 244 (1963). - 4. GoLr, K. H., Zschr. ärztl. Fortb. 56, 671 (1962). - 5. GolL, K. H., Medikamentum 5, 151 (1962). - 6. AMmon, R. und F. J. ZAPP, Klin. Wschr. 33, 759 (1955). - 7. de la Huerga, J., C. Yesnick und H. Popper, Amer. J. Clin. Path. 22, 1126 (1952). - 8. Herzfeld, E. und $C_{H .}$ STUMPF, Wiener klin. Wschr. 67, 45 (1955). - 9. JORGENSEN, K., Scand. J. Clin. Laborat. Invest. 11, 282 (1959). - 10. KALOw, W. und H. A. LINDSAY, Canadian J. Biochem. 33, 568 (1955). - 11. Kommerell, B. und F. H. Franken, Dtsch. med. Wschr. 81, 1959 (1956). - 12. MaIN, A. R., K. E. Mrles und P. E. Braid, Biochem. J. 78, 769 (1961). - 13. LAMotrA, R. V., H. M. WII-
LIAMS und H. J. Wetstone, Gastroenterology, Baltimore 33, 50 (1957). - 14. PIrz, W., Klin. Wschr. 36, 1017 (1958). - 15. RIDER, J. A., J. L. Hodges und J. Swader, J. Laborat. Clin. Med., St. Louis 50, 376 (1957). - 16. SaILER, S. und H. BraUNSTEINER, Klin. Wschr. 37, 986 (1959). - 17. SCHÄFER, C., W. Döpke, K. H. Goll und'W. Görthe, Arzn.-Standard. 8, 84 (1967). 18. Homann, W., Naunyn-Schmiedeberg's Arch. exper. Path. 224, 176 (1955). - 19. STAHL, E., Dünnschichtchromatographie. II. Aufl., S. 829, Reag. Nr. 88 und S. 855 Reag. Nr. 261. Springer Verlag Berlin-Heidelberg-New York (1967). - 20. TAYLOR, Elmore H., Lloydia 27 (2), 96 (1964). - 21. WALDi, D. Naturwissenschaften 50, 614 (1963).

Dr. med. K. H. Goll und Dipl.-Chem. J. Gartzke DDR 108 Berlin Unter den Linden 40 